УДК 621.793 .14

\author{
Л.А. Фоменко ${ }^{1}$, Т.Н. Соколова², Е.Л. Сурменко² \\ ${ }^{1}$ Саратовский государственный аграрный университет \\ им. Н.И.Вавилова, Саратов, Россия \\ ${ }^{2}$ Саратовский государственный технический университет \\ им. Ю.А. Гагарина, Саратов, Россия
}

ПРИМЕНЕНИЕ ВОЛОКОННЫХ ЛАЗЕРОВ ДЛЯ ЛАЗЕРНО-ЭЛЕКТРОХИМИЧЕСКОЙ РЕСТАВРАЦИИ ЗАЩИТНЫХ ПОКРЫТИЙ ТОНКОПЛЕНОЧНЫХ ГИБРИДНЫХ ИНТЕГРАЛЬНЫХ СХЕМ

\begin{abstract}
Обсуждается разработанная технология реставрации дефектов защитных покрытий элементов топологии тонкопленочных гибридных интегральных схем (ГИС), в основе которой лежит процесс локального лазерного электрохимического осаждения золота и сплава олово-висмут на медь излучением волоконного лазера. Натурные испытания реставрированных ГИС показали удовлетворительное качество локальных лазерно-электрохимических осадков золота и сплава олово-висмут, а также сохранность номиналов тонкопленочных резисторов плат ГИС в оптимальных режимах лазерного электролиза.

Ключевые слова: гибридные интегральные схемы, волоконный лазер, лазерно-электрохимическое осаждение металлов, элементы топологии, электролиз, реставрация.

\author{
L.A. Fomenko ${ }^{1}$, T.N. Sokolova ${ }^{2}$, E.L. Surmenko ${ }^{2}$ \\ ${ }^{1}$ Saratov State Agrarian University named after N.I. Vavilov, \\ Saratov, Russian Federation \\ ${ }^{2}$ Yuri Gagarin State Technical University of Saratov, \\ Saratov, Russian Federation
}

\section{FIBER LASER APPLICATION IN LASER-ELECTROCHEMICAL RESTORATION OF PROTECTIVE COATINGS OF THIN-FILM HYBRID INTEGRATED CIRCUITS}

\footnotetext{
Paper describes the developed technology of restoration of defects in the protective coatings of the elements of the topology of thin-film hybrid integrated circuits (HIC). The restoration technology is based on local fiber-laser electrochemical deposition of gold and an alloy of tin-bismuth in copper. Fullscale tests of restored HIC showed satisfactory quality of local laser-electrochemical gold and tinbismuth precipitation, as well as the preservation of the values of the thin-film resistors boards of HIC in the optimal regimes of laser electrolysis.

Keywords: hybrid integrated circuits, fiber laser, laser-electrochemical deposition of metals, elements of the topology, electrolysis, restoration.
} 


\section{Введение}

Производство тонкопленочных ГИС предусматривает нанесение защитных покрытий элементов топологии золотом или сплавом олововисмут. Покрытие производится либо в «окнах» фотолитографической маски, либо с помощью технологических перемычек. Из-за несовершенства технологии возникают дефекты защитного покрытия в виде непокрытых мест или протравов, дающие до половины от общего числа бракованных ГИС. При средней стоимости платы ГИС от 500 до 5000 руб./шт. реставрация защитных покрытий является экономически целесообразной операцией.

Если толщина защитных покрытий равна 2-6 мкм, то дефекты не могут быть устранены традиционными методами химической металлизации из растворов, поскольку небольшая селективность осаждения металла быстро исчезает уже при нанесении первых слоев защитного покрытия на месте локализации дефекта [1]. Поэтому регенерация бракованных плат ГИС сводилась, как правило, к химическому растворению металлизированных слоев плат и повторным технологическим операциям напыления, химической и электрохимической металлизации и фотолитографии.

При локальном лазерном нагреве границы металл - электролит [2] селективность осаждения металла значительно повышается, при этом важную роль играет паровая кавитационная модуляция скорости реакции лазерного электроосаждения (ЛЭО) металлов [3]. Иногда это приводит к пиролитическому режиму осаждения металла, что было обнаружено впервые при ЛЭО $\mathrm{Au}_{1}$ из термически неустойчивого раствора $\mathrm{KAu}(\mathrm{CN})_{2}$ вблизи потенциала коррозии $\mathrm{Cu}$-катода. При этом за счет образующегося, сильно поглощающего лазерное излучение коррозионного слоя $\mathrm{Cu}_{2} \mathrm{O}$ возникает яркая вспышка, обусловленная паровым кавитационным коллапсом при протекании пиролитической реакции осаждения золота, которая поддерживается далее в автокаталитическом режиме за счет выделения тепла при сгорании летучих продуктов пиролиза $\left(\mathrm{HCN}\right.$ и $\left.\mathrm{H}_{2}\right)$, что позволяет обеспечить быстрое устранение дефектов защитных покрытий и увеличить процент выхода годных ГИС. 


\section{1. Методика эксперимента}

Разработана технология реставрации защитных покрытий ГИС, в основе которой лежит процесс локального лазерного электроосаждения (ЛЭО) золота и сплава олово-висмут на медь. Используемая технологическая установка на базе волоконного лазера ИПМ 100 оснащена оптической системой типа УОСЛ, системой телемониторинга, устройством двухкоординатного перемещения с управлением от ПК, специальной электрохимической ячейкой с двухкоординатным игольчатым микроконтактом. Ячейка снабжена системой периодического охлаждения дна, включаемой после обработки серии бракованных плат ГИС для предотвращения паразитарного разогрева электролита. Параметры лазерного излучения: максимальная мощность $P_{\max }=120 \mathrm{~B}$, длина волны $\lambda=1070$ нм, поляризация случайная, качество пучка $M^{2}=1,05$. Преимущество применяемого излучателя перед ранее используемым [3] - в потребляемой мощности 0,24 кВт против 3,5 кВт, а также в отсутствии двухконтурного охлаждения и малом весе -8 кг. Схема установки реставрации представлена на рис. 1.

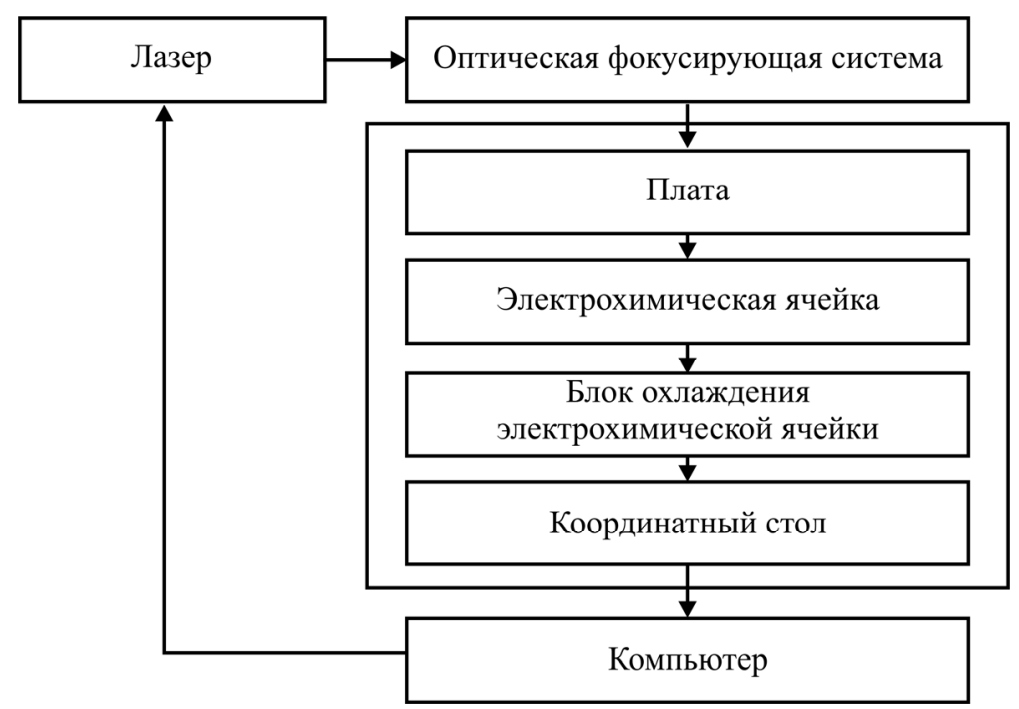

Рис. 1. Экспериментальная схема установки реставрации плат

Катодами служили платы ГИС СВЧ; в качестве анодов использовали золотую фольгу (для ЛЭО золота) и фольгу из олова марки М.01 (для ЛЭО сплава олово-висмут). 
Рабочие электролиты приготавливались на основе деионизированной воды с удельной электропроводностью $9,03 \cdot 10^{-7} \mathrm{CM} / \mathrm{cm}$ и реактивов (г/л): $\mathrm{SnSO}_{4}-50 ; \mathrm{Bi}\left(\mathrm{NO}_{3}\right)_{3} \cdot 5 \mathrm{H}_{2} \mathrm{O}-1 ; \mathrm{H}_{2} \mathrm{SO}_{4}-100 ; \mathrm{NaCl}-0,5$; «ОС-20» - 5 (для ЛЭО сплава олово - висмут); $\mathrm{KAu}(\mathrm{CN})_{2}-12$; лимонная кислота - 30; цитрат калия - 40 при $\mathrm{pH}=5$ (для ЛЭО золота). Зна-

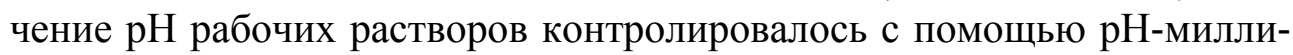
вольтметра рН-201 с точностью $\pm 0,005$ и, в случае необходимости, корректировалось добавками растворов $\mathrm{KOH}$ или $\mathrm{NaOH}$.

\section{2. Обсуждение результатов}

Селективность осаждения металлов количественно оценивалась по коэффициенту лазерного ускорения $K_{\mathrm{Y}}$, представляющему собой отношение плотности тока $i$ лазерно-стимулированного процесса к «темновой плотности тока» $i_{T}$. Оптимизация процесса производилась посредством подбора катодного потенциала $E$ и интенсивности облучения $W$, обеспечивающих максимальное значение коэффициента ускорения $K_{\mathrm{Y}}$.

Время заращивания $\tau_{0}$ «точечного» дефекта определялось как отношение характерной толщины $L_{0}$ защитного покрытия к скорости осаждения $j_{0}$ металла внутри сфокусированного лазерного пятна. Величина $j_{0}$ связана со среднерадиальной плотностью тока $i_{0}$ внутри сфокусированного лазерного пятна законом Фарадея. Величина $i_{0}$ определялась в отдельных экспериментах, выполняемых по методике локального фотолитографического катода [4].

Технологическая схема реставрации включает: идентификацию дефектов; обезжиривание, промывку и монтаж плат ГИС на оснастке; локальное лазерное электроосаждение металла защитного покрытия по месту дефекта; демонтаж оснастки; промывку и сушку.

Время обработки $\tau$ дефектной платы ГИС рассчитывалось из эмпирического соотношения [5]:

$$
\tau=\frac{S_{\Sigma}}{\pi r_{0}^{2}} \tau_{0}+\tau_{1}+\tau_{2}
$$

где $S_{\Sigma}$ - суммарная площадь дефектов; $\tau_{1} \approx 3$ мин- время, затрачиваемое на монтаж платы на оснастке; $\tau_{2} \approx 0,5$ мин - длительность технологической паузы периодического охлаждения электролита в расчете на одну плату ГИС. 
Расход металла $M$ может быть оценен по уравнению [5]

$$
M=\rho \cdot L_{0} \cdot S_{\Sigma}\left(1+\frac{\alpha\left(S-S_{\Sigma}\right)}{\pi \cdot r_{0}^{2} \cdot K_{Y}^{*}}\right),
$$

где $\rho$ - плотность металла; $L_{0}$ - толщина покрытия; $S$ - общая площадь топологии ГИС; $\alpha-$ коэффициент, характеризующий электрическую несвязность топологии ГИС, равный $0<\alpha<1$.

Для определения коэффициента $\alpha$ можно воспользоваться статистическим анализом чертежей конструкторской документации плат ГИС в соответствии с формулой [5]

$$
\alpha=\frac{1}{N} \sum_{i=1}^{n}\left\{\frac{1}{N} \sum_{j=1}^{n} \cdot \sum_{k=1}^{m} \frac{\left(S_{i j k}\right)^{2}}{S_{i}^{2}} \cdot \frac{1}{\sqrt{2 P_{i} \cdot \delta_{j}}} \cdot \exp \left[\frac{\left(S_{i j}^{-\alpha_{i}}\right)^{2}}{2 \delta_{i}^{2}}\right],\right.
$$

где $i$ - номер платы; $j$ - номер участка топологии платы; $k$ - номер дефекта; $S_{i}$ - площадь топологии $i$-й платы; $S_{i j}$ - площадь $j$-го участка топологии $i$-й платы; $S_{i j k}-$ площадь $j$-го участка топологии $i$-й платы, на которую попадает $k$-й дефект; $S_{i}$ и $\alpha_{i}$ - параметры нормального распределения Гаусса, рассчитываемые из соотношений:

$$
\sigma_{i}^{2}=\frac{1}{n} \sum_{i=1}^{n}\left(S_{i j}-S_{i}\right)^{2}, \alpha_{i}=\sum_{j=1}^{n} S_{i j} \cdot P_{j},
$$

где $S_{j}$ - средняя площадь топологии $j$-го участка топологии платы; $P_{j}$ - вероятность появления $j$-го участка топологии в конструкции платы ГИС.

Периодичность смены электролита в электрохимической ячейке определяется исходя из предельного количества плат П, обрабатываемых в одной порции раствора:

$$
\Pi=\frac{C\left(C_{0}-C_{k}\right)}{M} \cdot V_{я},
$$

где $C_{0}$ и $C_{k}$ - исходная и предельно допустимая концентрация соли металла в растворе электролита; $C$ - содержание металла соли по массе; $V_{\text {я }}$ - рабочий объем электрохимической ячейки; $M-$ средний расход драгоценного металла на плату, мг.

Параметры процесса реставрации ГИС представлены в таблице. 
Основные технические характеристики процесса лазерной электрохимической реставрации защитных покрытий ГИС

\begin{tabular}{|l|c|c|}
\hline \multicolumn{1}{|c|}{ Параметр } & \multicolumn{2}{c|}{ Металл покрытия } \\
\cline { 2 - 3 } & золото & олово-висмут \\
\hline Оптимальный катодный потенциал $E$, В (н.в.э.) & $-0,89$ & $-0,76$ \\
\hline Оптимальная интенсивность лазерного облучения $W$, кВт/см ${ }^{2}$ & 21 & 21 \\
\hline Оптимальная скорость осаждения металла $j_{0}$, мкм/мин & 12,12 & 10,9 \\
\hline Оптимальный коэффициент лазерного ускорения $K_{\mathrm{Y}}$ & 150 & 250 \\
\hline Разрешающая способность $r_{0}$, мкм & $30-35$ & $28-32$ \\
\hline Максимальный размер платы ГИС, мм & $48 \times 60$ & $48 \times 60$ \\
\hline Погрешность, нанесения осадков, $\%$ & $6-9$ & 7 \\
\hline Предельный размер дефектов, мм & $2-3$ & $2-3$ \\
\hline Характерная толщина покрытия $L_{0}$, мкм & 2 & 6 \\
\hline Средняя производительность труда, плат/ч & 8 & 4 \\
\hline Средний расход драгоценного металла $M$, мг/на одну плату & 1,533 & - \\
\hline Рабочий объем ячейки $V_{\text {я }, \text { см } 3}{ }^{3}$ & 60 & 60 \\
\hline $\begin{array}{l}\text { Предельное количество плат, обрабатываемых в порции } \\
\text { раствора, П }\end{array}$ & 386 & 115 \\
\hline
\end{tabular}

Из таблицы видно, что применение технологии лазерно-электрохимической реставрации может обеспечить годовую программу работ в объеме 8-10 тыс. шт. в расчете на одну установку. Средний расход электролита при этом составит всего 3 л. Расход драгоценного металла не превысит 20 г, что сопоставимо с потерями при регенерации золота из электролита после стравливания защитного покрытия бракованных плат ГИС.

Натурные испытания показали удовлетворительную микроструктуру и адгезию локальных лазерно-электрохимических осадков золота и сплава олово-висмут, свариваемость (золото) и паяемость этих осадков, а также устойчивость функциональных свойств локальных покрытий в условиях жестких термоциклов и сохранность номиналов тонкопленочных резисторов плат ГИС в оптимальных режимах лазерного электролиза.

Натурные испытания показали удовлетворительную микроструктуру и адгезию локальных лазерно-электрохимических осадков золота и сплава олово-висмут, свариваемость (золото) и паяемость этих осадков, а также устойчивость функциональных свойств локальных покрытий в условиях жестких термоциклов и сохранность номиналов тонкопленочных резисторов плат ГИС в оптимальных режимах лазерного электролиза. 


\section{Заключение}

Технология лазерно-электрохимического осаждения металлов излучением волоконных лазеров может быть использована не только для реставрации защитных покрытий планарных ГИС. Она перспективна и при изготовлении топологии непланарных специальных интегральных схем (СИС) электронных устройств предварительного усиления, размещаемых на корпусах антенн, датчиков, гироскопов, с целью достижения максимального отношения сигнал/шум. Такие СИС имеют высокую стоимость, что оправдывает применение лазерно-электрохимической технологии для их реставрации.

Работа выполнена на оборудовании ЦКП «Лазерные и оптические технологии» (Поволжский филиал), ФЦП «Исследования и разработки по приоритетным направлениям развития научно-технологического комплекса России на 2007-2013 годыр, мероприятие 5.2. Развитие сети центров коллективного пользования научным оборудованием, ГК № 02.552.11.7021 (08.05.2007).

\section{Список литературы}

1. Никандрова Л.Н. Химические способы получения металлических покрытий. - Л.: Машиностроение, 1971. - 104 с.

2. Серянов Ю.В., Аравина Л.В. Лазерно-химические реакции для получения элементов ИЭТ // Обзоры по электронной технике. Серия 7. Технология, организация производства и оборудование. - М.: ЦНИИ «Электроника», 1990. - Вып. 11 (1554). - 42 с.

3. Серянов Ю.В., Фоменко Л.А. Роль паровой кавитационной модуляции скорости реакций лазерного осаждения металлов // Электрохимия. - 1998. - Т. 73, № 5. - С. 1066-1071.

4. Puippe J.Cl., Acosta R.E., Gutfeld R.J von. Investigation of laserenhanced electroplating mechanisms // J. Electrochemical Society. - 1981. Vol. 128, no. 12. - P. 2539-2545.

5. Серянов Ю.В., Фоменко Л.А., Соколова Т.Н., Чеботаревский Ю.В. Электрохимическая обработка металлов. - Саратов: Изд-во СГТУ, 1998. - 124 c. 


\section{References}

1. Nikandrova L.N. Khimicheskie sposoby polucheniia metallicheskikh pokrytii [Chemical methods of metal coatings obtaining]. Leningrad: Mashinostroenie, 1971. 104 p.

2. Serianov Iu.V., Aravina L.V. Lazerno-khimicheskie reaktsii dlia polucheniia elementov IET [Laser chemical reactions for obtaining of electronic devices elements]. Obzory po elektronnoi tekhnike. Seriia 7. Tekhnologiia, organizatsiia proizvodstva i oborudovanie. Moscow: Electronika, 1990, vol. 11 (1554). 42 p.

3. Serianov Iu.V., Fomenko L.A. Rol' parovoi kavitatsionnoi moduliatsii skorosti reaktsii lazernogo osazhdeniia metallov [Role of the steam cavitation modulation of laser metal deposition reactions velocity]. Elektrokhimiia, 1998, vol. 73, no. 5, pp. 1066-1071.

4. Puippe J.Cl., Acosta R.E., Gutfeld R.J von. Investigation of laserenhanced electroplating mechanisms. J. Electrochemical Society, 1981, vol. 128 , no. 12 , pp. 2539-2545.

5. Seryanov Iu.V., Fomenko L.A., Sokolova T.N. Elektrokhimicheskaia obrabotka metallov [Metal Electrochemistry Treatment]. Saratov: Saratovskii gosudarstvennyi tekhnicheskii universitet, 1998. 124 p.

Получено 15.09.2015 